\title{
Los cumpas de la cordillera San Lucas Cuisnahuát y San Cristóbal de Jayaque
}

DOI: http://dx.doi.org/10.5377/koot.v0i10.6704

URI: http://hdl.handle.net/11298/790

\author{
Mtro. Julio Martínez. \\ Director Escuela de Antropología \\ Universidad Tecnológica de El Salvador \\ julio.marttinez@utec.edu.sv
}

\section{Resumen}

Una inundación da sentido a la tradición de los cumpas, el hermanamiento de los pueblos incluye a los santos y la comunidad y sirvió originalmente para alojar a quienes habían sufrido del desborde del río. Es la excusa perfecta para efectuar la introducción de un elemento religioso, los santos se convierten en compadres de tal forma que tienen el compromiso de visitarse mutuamente cada año para mantener la tradición.

Cabe preguntarse si el sincretismo que se adopta en el ritual tradicional es el resultado de que la tradición de visitarse entre los comunitarios de los pueblos indígenas viene desde muchos antes de la llegada de la evangelización por parte de los españoles. En el recorrido a lo largo del camino entre San Lucas y San Cristóbal, que culmina con la topa de los cumpas hay caminata, intercambio de regalos, fraternización, baile, chicha y chaparro. Después de algunos meses, inicia el camino de vuelta.

El encuentro sirve además para bailar, entretenerse y beber. La iglesia institucional prefiere asumir que no le interesa la fiesta popular, solo el acto solemne.

Palabras clave: Religiosidad; Indígenas; Cultura; Identidad cultural; Compadres.

\begin{abstract}
A flood gave meaning to the tradition of los cumpas; the brotherhood of two towns embraced their saints and their communities, which originally served to shelter those who had suffered the overflowing of the river. It was the perfect excuse for the introduction of a religious element: the saints became compadres-pals-- in such a way that they committed each other to visit every year in order to keep the tradition alive.
\end{abstract}


It is worth asking ourselves if the syncretism adopted in the traditional ritual is the result of the original visits between the indigenous peoples and their communities-- an ancient practice from long before the arrival and evangelization of the Spanish conquerors. During the journey between San Lucas and San Cristóbal, which ends with the meeting of the cumpas, you can find an exchange of presents, fraternization, a dance, chicha--alcoholic drink made from fermented corn-- and moonshine. After a few months of celebration, the way back begins.

Since the encounter between the two saints also serves the purpose of entertaining, dancing and drinking, the institutional church prefers to assume that it is only interested in the solemn religious act thus ignoring the popular celebration

Keywords: Religiosity; Indigenous people; Culture; Cultural identity; Compadres.

\section{Introducción}

Esta investigación ha tenido varios escenarios, documentalmente se ha abordado más en forma de artículos cortos usados para reproducirse en medios de comunicación escritos. Estos, lastimosamente no tienen la profundidad ni amplitud que permita tener una visión integrada de los distintos aspectos culturales de la celebración.

Acompañamiento de la romería, entrevistas a profundidad, observación y la revisión de documentos de la historia permiten un abordaje más académico, y eso ha permitido contar con un texto que puede prometer un trabajo con mayor raigambre e interpretación encarnada en la visión de los pobladores.

Las variadas tradiciones salvadoreñas en realidad no son solo nuestras, la cultura local es una amalgama de diversos y variados elementos que han conformado la tradición mesoamericana.

No sería raro que ahora que hablamos de "cumpas", encontremos en otros lugares de Centroamérica y México tradiciones similares, algunas más antiguas que otras.

Los cumpas de la cordillera tienen varias cualidades que buscamos resaltar en este artículo: una historia que refiere a diluvios y los efectos positivos que se obtienen en la relación naturaleza y cultura; la relación de la sociedad comunitaria con las autoridades eclesiales locales; las costumbres de los pueblos originarios

1 "Cumpas" es una manera de expresar coloquialmente y en particular entre campesinos e indígenas el título de "compadre" 
mezcladas con la tradición católica de los conquistadores expresada en formas de evangelización que determinan la apropiación y transformación cultural del indígena; la excusa del ritual religioso para mantener viva la fraternidad de los pueblos a lo largo de la historia; el poder de la organización de la comunidad y la ritualidad que une a las comunidades.

Los cumpas de la cordillera se refieren a San Lucas, patrono de Cuisnahuát y a San Cristóbal patrono de Jayaque, y busca descubrir el origen de los pueblos y la génesis de la tradición.

Trata de comprender las relaciones comunitarias y el imaginario religiosopagano que existe en la población de la cordillera, como un elemento de cohesión social de las cofradías y motor de la tradición.

\section{Origen de los encuentros de los santos o patronos locales}

En algún momento de la historia, a finales del siglo XVII, hace más de trescientos años, cuando Cuisnahuát no estaba donde se encuentra en la actualidad sino en Tonalá cerca de Mizata en la costa del pacifico salvadoreño, hubo un enorme temporal, un invierno atroz que hizo que el Río Grande de Sonsonate $^{2}$ se desparramara tanto que inundó al pueblo.

La gente no sabía dónde ir para protegerse, se encontraban desamparados y no tenían que comer. El miedo les acechaba en forma de lluvia, esa lluvia que ha servido para la vida, para la fertilidad, para fructificar en esa ocasión sirvió para atemorizar e inundar al pueblo. Esta historia es atribuida a Francisco Antonio de Fuentes y Guzman quien fue además de cronista del Reyno de Goathemala, uno de los Alcaldes de Totonicapán y de Sonsonate cerca del año 1700 (MCN Biografías, 2017).

De acuerdo a los lugareños, en ese momento se estableció la relación solidaria y fraterna de los santos:

"San Cristóbal patrón de Jayaque se puso a la orden para que San Lucas, patrono de Cuisnahuát, pudiera llevar a su pueblo allá a la cumbre, detrás del cerro de los coyotes, detrás del Xayatepeque”, (Pedrina Figueroa Pérez, 2017)

Ese hecho sucede el día 23 de julio de algún año del siglo XVII. San Lucas se queda en la casa de San Cristóbal durante casi seis meses ya que el 27 de noviembre, ambos santos, regresan a Cuisnahuát.

2 El río Grande es el actual Sensunapán. Aunque en algunas tradiciones orales, el río desbordado es el llamado "Banderas", que resulta más lógico por su cercanía con la región. 
Posterior a la inundación, los habitantes de Tonalá decidieron buscar un sitio en donde hubiera menos posibilidades de sufrir de nuevo de las inundaciones, ese nuevo sitio es Cuisnahuát o Kwisnawat (Huitznahuac o Huitsnahuic; (Junto al espino o los cuatro espinos), a inicios del siglo XVIII. Luego, ya en 1770 formó parte del curato de Guaymoco (actual Armenia), y el 12 de junio de 1824 del departamento de San Salvador, luego:

"En 1827 fue segregado del partido de Opico y anexado al de Izalco; el 22 de mayo de 1835 pasó a jurisdicción del partido de Quezaltepeque. El 30 de septiembre de 1836 quedó incorporado definitivamente al distrito de Izalco. Para el año de 1859 tenía 750 habitantes, y la ocupación principal era el cultivo y explotación del bálsamo". (FISDL, 2010)

Las cordilleras en El Salvador reflejan en muchos casos pueblos ancestrales, lugares donde mayas, pok mames, lencas, ulúas, kakawiras y pipiles establecieron sus pueblos. Estas cordilleras ubicadas en distintas partes del país son:

1. La Alotepeque - Metapán,

2. La Apaneca Ilamatepec,

3. La del Bálsamo,

4. La Nahuaterique,

5. La Cacahuatique y

6. La Jucuarán- Intipucá.

Hoy nos ubicamos en la Cordillera del Bálsamo, que corre en paralelo a la costa salvadoreña, en donde en un tiempo existió propiedad colectiva o comunal. De hecho, Cuisnahuát obtuvo su título ejidal lo obtuvo el 20 de junio de 1866. (FISDL, 2010)

Jayaque, por otra parte, tiene su origen en el pueblo de Opico ${ }^{3}$, adonde pertenecía su población originariamente, sin embargo, en el sitio actual adonde se pasaron en 1770 luego de salir de Opico por causa de varias plagas, ya habitaban algunos indígenas:

"Su nombre autóctono actual, Jayaque, es corrupción de Xayacatepec, toponímico que en idioma náhuat significa "cerro de los enmascarados", de xayacat (faz fisonomía, cara, enmascarado) y tepec (cerro, montaña, localidad). En 1550 tenía unos 500 habitantes". (Mi pueblo y su gente, 2018)

Un informe de la municipalidad de Jayaque, del siglo XIX citado por el FISDL, menciona lo siguiente:

"Entre las antigüedades de Jayaque se cuentan varios libros escritos en náhuat cuyas fechas se remontan hasta el año de 1666, época en que el Ilmo. Obispo

3 Opico se encuentra unos 18 kilómetros al norponiente, no en la cordillera sino en el Valle de Zapotitán. 


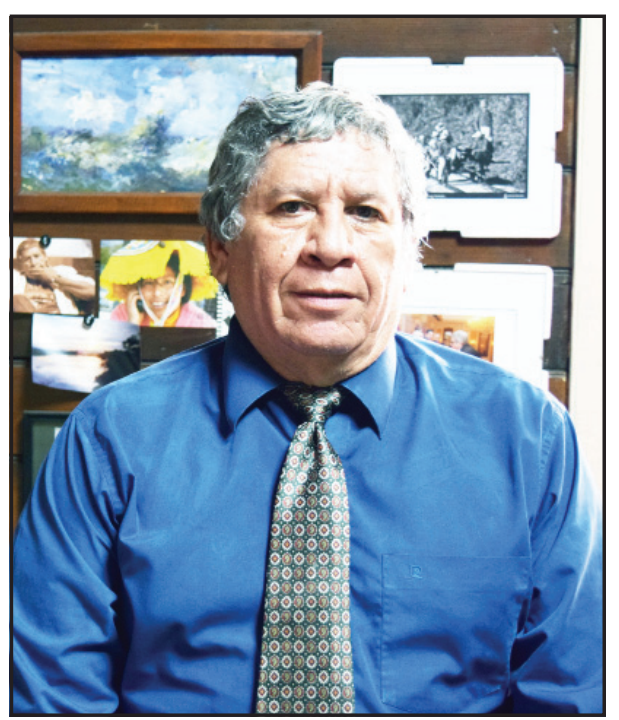

Julio Martínez

de Guatemala visitó el pueblo en visita canónica, referencia que hacen los libros de cuenta de las cofradías”. (Alcaldía Mpal. de Jayaque, 1861)

La tradición religiosa del "Encuentro de los cumpas" ya había hecho su aparición y las cofradías como tales ya se habían organizado, en un pueblo en el que los indígenas eran la absoluta mayoría y quienes tenían establecido las formas de relacionarse con otros pueblos, y de emplearse en actividades agrícolas que tenían una característica de procesamiento artesanal, y que además significaba económicamente muchísimo para el país completo:

"El corregidor intendente don Antonio Gutiérrez y Ulloa dice que, en 1807, Jayaque era "Pueblo de indios... muy destruido y de mal temperamento y los pocos naturales dedicados al cultivo del añil en las haciendas inmediatas de particulares". (Mi pueblo y su gente, 2018)

Otras versiones en segundo lugar acerca del origen también buscan explicar este "compadrazgo de santos" es que, desde tiempos ancestrales, los pueblos originarios de Cuisnahuat y Jayaque se hacían intercambios de ofrendas de alimentos como parte de un hermanamiento de comunidades, y en este marco, la evangelización durante la época colonial aprovechó los vínculos que se habían establecido para incorporar a los nuevos santos: San Lucas, patrono de Cuisnahuat y San Cristóbal patrono de Jayaque.

Una tercera versión adicional explica que los dos pueblos tenían rivalidades y que los sacerdotes coloniales aprovecharon las imágenes de San Lucas y San Cristóbal como símbolo de reconciliación. 
No es una cuestión corriente encontrar este tipo de visitas entre cofrades y sus respectivos santos, de hecho, un sacerdote de un pueblo del oriente del país, en San Vicente, explicaba que:

"Eso de andarse visitando los santos no sucede por estos lares" (Ramírez, 2018)

No es común pero tampoco el hecho social o religioso es único. Existen otros casos de encuentros, "topadas" o "topas" de santos como también se les conoce a estas visitas, en particular al momento cumbre en el que los santos salen a recibir al otro que llega de huésped.

También hay otra tradición similar en el "Encuentro de los niños zarcos y el niño Jesús" que se realiza entre San Ramón y Candelaria del Departamento de Cuzcatlán con San Pedro Nonualco del Departamento de la Paz.

Sobre la antigua Aculhuaca en la actual Ciudad Delgado, en la capital San Salvador y fundamentalmente sobre el patrono Santiago, Baratta expresa que:

"El pito de caña deshilacha la melodía en del son de la "topada" en la ceremonia tradicional en que el Cristo de la otra Iglesia del Calvario viene a topar al Santo patrono Santiago que celebran ese día" (Baratta, 1934)

De acuerdo a uno de los miembros de la cofradía en Cuisnahuát, la tradición puede tener un poco más de antigüedad que el siglo XVII, pues nos indica que:

"Yo tengo los libros (originales) de la tradición y en ellos se alcanza a leer que la tradición se origina en el año 1666, pero la tradición es de mucho más atrás porque tengo unos libros que no se pueden leer, y están solo en nahuat" (Miguel Angel Quintanilla, 2018)

¿Es que acaso como menciona una de las versiones del origen del encuentro, los sacerdotes aprovecharon la existencia de una atadura entre los pueblos para agregar sincréticamente a los santos en su afán evangelizador? Es posible, muy posible en particular si notamos como la actividad del encuentro no es únicamente una actividad religiosa.

Un elemento agregado es la existencia de libros antiguos, algunos incluso en náhuat. Hay pues, una aseveración acerca de la tenencia de los tales libros, antiguos y patrimonio de la comunidad y del país, así como también es evidente que se tiene un cierto recelo y un guardar los documentos con mucha desconfianza (¿o es solamente un ritual?). ¿Se refieren los libros en náhuat al encuentro de los cumpas de forma cristiana o el encuentro reúne otras cualidades que se alejan de lo cristiano, una tradición pagana precolombina?, ¿Existen de verdad esos libros?: 
"Los libros no se pueden enseñar, a menos que tengamos una reunión en la cofradía y nombren a tres para que vayan a enseñarlos" (Miguel Angel Quintanilla, 2018)

Esta tradición de los cumpas, como también ha sucedido con diversos rituales tradicionales, ha sufrido modificaciones pues,

“aquí no era la tradición entre solo nosotros, tenía que ver Armenia, tenía que ver San Julián ${ }^{4} .$. tenía más valor que ahora... se elegían unas personas que se llamaban cabecillas, tanto de hombres como de mujeres. Las mujeres se hacían cargo de la cocina, la de los hombres se encargaban de conseguir (recursos)" (Miguel Angel Quintanilla, 2018)

Todo ello calza perfectamente con los hechos históricos que indican que tanto Cuisnahuát como San Julián en 1770 pertenecían al Curato de Guaymoco 5 o como lo indica su nombre en la actualidad, Armenia. Como cambia todo, también esta tradición y vínculos se han modificado.

\section{Fotografía 1}

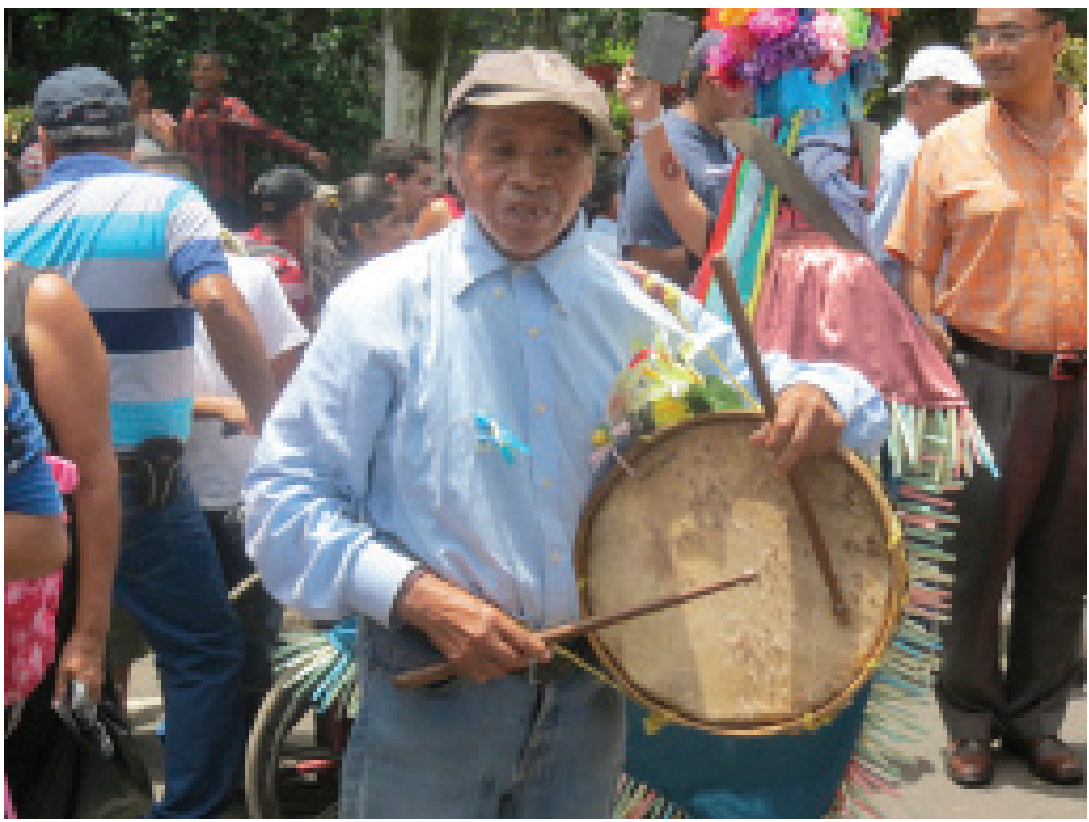

Tamborilero en la Romería de Cuisnahuat.

4 Pueblos cercanos que se encuentran entre Cuisnahuát y Jayaque.

5 Guaymoco o Armenia se encuentra 15 kilometros al norte de Cuisnahuát 


\section{El papel de las cofradías}

La cofradía es un grupo de personas que se consideran a sí mismos como hermanos fraternos en su unidad en torno a una deidad o santo de la iglesia, en algunas cosas es una asociación legalmente establecida. En el pueblo del patrono San Lucas hay muchos miembros de la cofradía, pero se puede valorar que es una tradición que puede perderse, debido a que en la generalidad de los miembros de las mismas pertenecen a la tercera edad.

"Cuisnahuát somos sesenta y cinco miembros, pero solo hay dos cipotes (jóvenes)" (Miguel Angel Quintanilla, 2018).

La cofradía usualmente es una entidad o sociedad privada, a pesar que el origen esté vinculado a los patronos locales, a sus santos, se puede pensar que también a la iglesia como institución. De hecho, existe una relación entre la entidad y los párrocos, solo que esta manera de implicarse no es en dependencia sino más bien se comprenden en planos distintos, unos a la estructura orgánica de la iglesia y los otros como representantes populares católicos.

Los cofrades pueden tener (las tienen) diferencias con los párrocos y no significa que sea una lucha de poder, es más bien que sus ámbitos son distintos, como bien decía uno de los líderes de Cuisnahuát

"ellos - los sacerdotes- son temporales en la comunidad, no forman parte de nosotros, es gente que está de paso. Los que mandan en la cofradía son los antiguos (locales), ellos los sacerdotes no" (Miguel Angel Quintanilla, 2018),

Aunque en esas palabras hay un dejo de rivalidades no resueltas, como indicando que la representación de la comunidad religiosa católica que tienen adoración por su santo y que llevan como cualidad distintiva la organización, preparación y ejecución de la peregrinación para el encuentro de los cumpas obedece a la población y no al sacerdote. Ellos y solo ellos no como desafío sino como reafirmación.

La mayor parte de las cofradías en la región de la cordillera del bálsamo son "de Gloria”, ni penitencial ni sacramental, sino dedicadas a la advocación de algún santo, para efectos de este estudio podremos mencionar las cofradías de:

- San Lucas Evangelista (Cuisnahuát), patrono de los médicos y los artistas

- San Cristóbal Mártir (Jayaque), patrono de los viajeros, conductores y motoristas

- San José (Talnique), patrono de los trabajadores

- San Antonio (San Antonio del Monte), patrono de los enamorados 
- y San Esteban Protomártir (Sacacoyo), patrono de los caballos, los albañiles y los carpinteros.

Todos ellos pueblos de la cordillera del bálsamo ubicada en el pacifico salvadoreño.

\section{Fotografía 2}

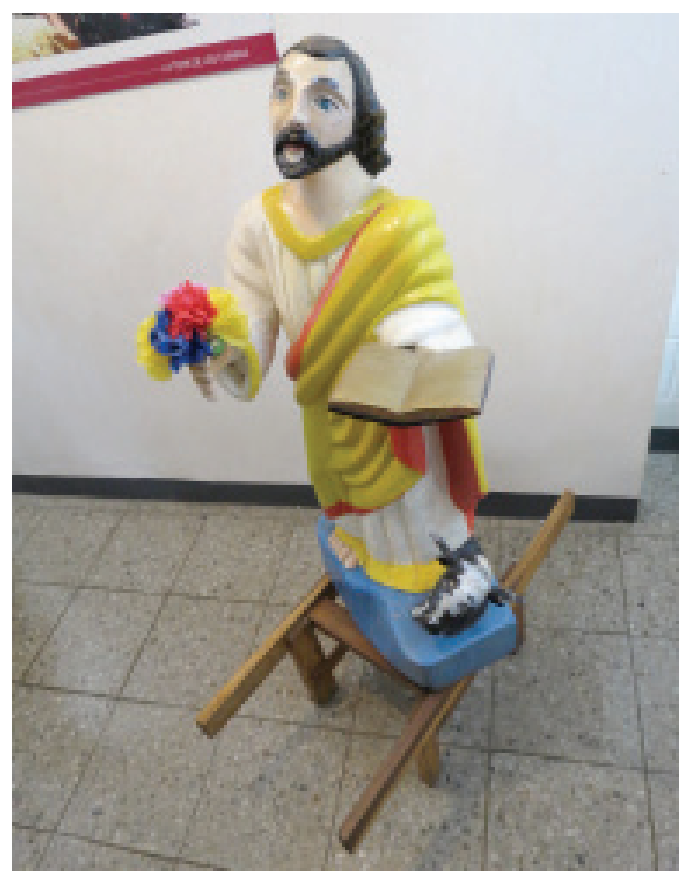

San Lucas en Casa de la Cultura de Jayaque. 


\section{Fotografía 3}

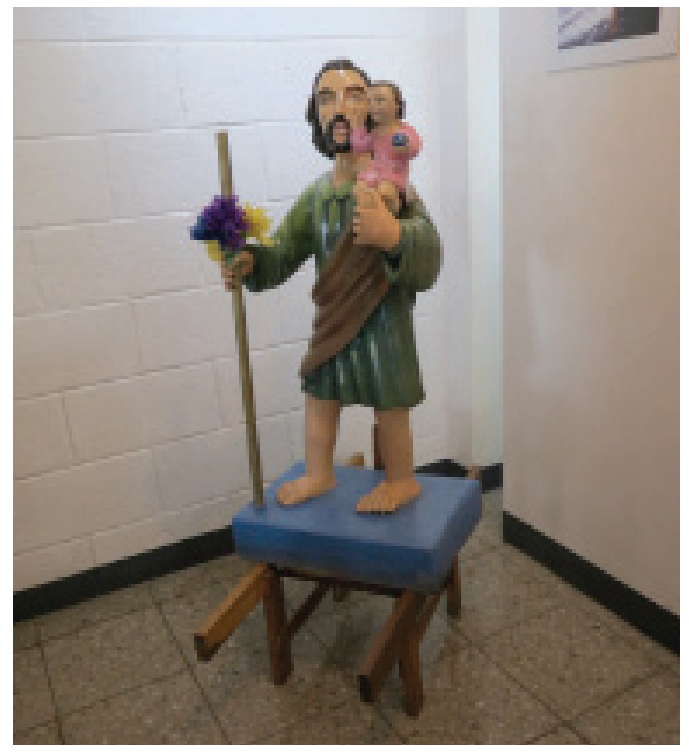

San Cristóbal en Casa de la Cultura de Jayaque.

\section{Fotografía 4}

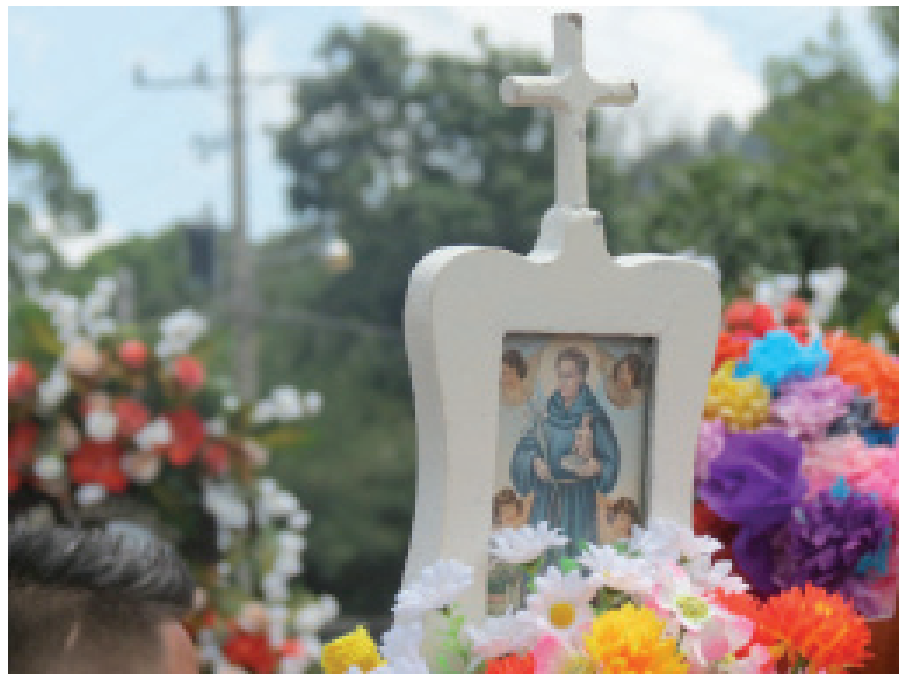

San Antonio llegando de San Antonio del Monte a Jayaque. 


\section{Fotografía 5}

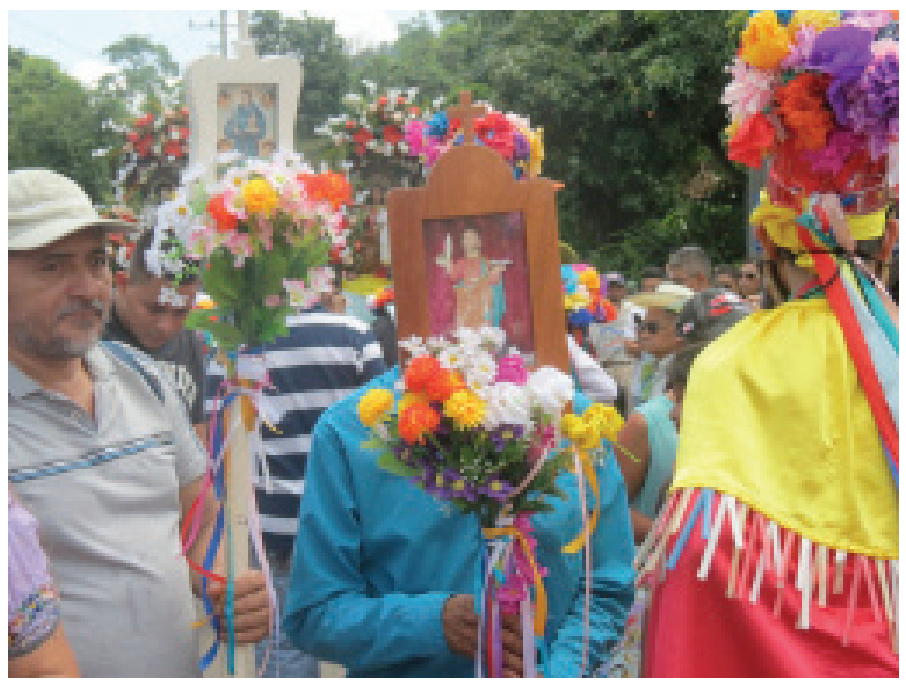

San Esteban de Tepecoyo. llegando a Jayaque.

La tradición anotada hace "compadres" a San Lucas y San Cristóbal, originalmente, sin embargo, las relaciones de las cofradías han hecho que se sumen los intercambios de tal manera que la visita de San Lucas a San Cristóbal ("los cumpas") y viceversa junta también a esos otros tres santos, es el encuentro de cinco santos que acompañan este ritual que original y significativamente es de dos.

"Llegando los peregrinos el 22 de julio a Tepecoyo, donde se efectúo el Encuentro, uniéndose las cofradías de San Antonio del Monte (Sonsonate) y del cantón San José Los Sitios de Talnique en La Libertad" (COMURES, 2015)

Aunque en efecto hay un amplio deseo de compartir, de unirse en la celebración, los “cumpas" San Lucas y San Cristóbal adquieren el carácter más representativo.

Más original.

Existe un protocolo formal y estilizado que posibilita el encuentro y adhesión a la romería de los cumpas originales, este mecanismo es realizado año con año e implica la elaboración de cartas y notas formales de solicitud para la visita o de invitación de "un santo a otro" de forma escrita.

En Cuisnahuát los intercambios, invitaciones y encuentros se dan de acuerdo al siguiente calendario, que en realidad refleja el calendario de actividades de intercambio de la región (Cuisnahuat, 2017): 
Mes de febrero

- El uno de febrero se hace la invitación a San Antonio del Monte

Mes de marzo

- En alguna fecha indeterminada San José los sitios invita a San Lucas, y se llevan cohetes de vara y tambor, hay encuentro de cumpas y se hace intercambio de regalos y flores.

Mes de Julio

- El cinco de julio se visita Tepecoyo para solicitar la posada para la llegada de San Lucas.

- El veintidós de julio, inicia la peregrinación, se llega a Tepecoyo, se rezan rosarios y hay una fiesta ofrecida por la cofradía anfitriona.

- El veintitrés de julio, la peregrinación continua hasta llegar a Curazao. Hay misa y desayuno y luego se parte para llegar a Jayaque.

Mes de Agosto

- La cofradía de San Antonio del Monte visita Cuisnahuát para invitar a la fiesta de su patrono. Pasan el día en la casa de habitación de la mayordoma y luego por la tarde van a la iglesia del santo a realizar "los encuentros".

Mes de octubre

- Del nueve al diecisiete de octubre se celebra la novena a San Lucas, durante la novena hay chilate, tamales. Se finaliza la novena con el baile del puro.

Mes de noviembre

- Entre el uno y el cinco de noviembre, la cofradía sale para ir a invitar a las otras cofradías de Jayaque, Tepecoyo, San Antonio y San José los sitios de Talnique, el propósito es recibirles en la peregrinación de retorno.

- El veinticinco se hacen los tamales que se llevarán al día siguiente a la cueva del Estocal, donde se montará un altar y además se rezará un rosario.

- El día veintiséis se llevan a cabo los encuentros de los santos: a la 9:00 a.m. con San José; a las 11:00 con San Cristóbal; a las 12:00 con San 
Esteban y las 12.30 con San Antonio del Monte. Por la noche se rezan rosarios para los santos.

- El día veintisiete los santos salen en procesión y se pide limosna- Ese mismo día a las 9:00 a.m. se ofrece el baile del puro y se presentan las capitanas

- El día veintiocho se hace una colecta de dinero en la población, juntamente con la cofradía de Jayaque.

Mes de diciembre

- Del uno al treinta y uno de diciembre inicia la novena a San Antonio

En este intercambio de notas no participan los párrocos, más bien parecen ser alejados por la cofradía o por voluntad propia. Es que el encuentro de los cumpas tiene algunos aspectos con los que la iglesia católica no se siente muy a gusto y que parecen desafiar el espíritu conservador y dogmático de la institución eclesial; y que pudieran estar vinculados a un pasado ancestral arraigado en las costumbres de los pueblos tales como el baile del puro, los intercambios de regalos y aunque no aparece es ineludible, la bebetoria de chicha y chaparro (Ruiz, 2017). Las notas de invitación y solicitudes de los cofrades quedan finalmente en poder de ellos mismos.

"El mayordomo de Cuisnahuát se queda con las cartas de invitación” (Miguel Angel Quintanilla, 2018)

Un elemento que protagoniza todo el ceremonial es la comprensión de que los santos adquieren animación en este lance, "San Antonio pide participar", "San Lucas irá en la fecha tal", "Se nos va a juntar San José".

Esto no queda solamente en la palabra sino también en el traslado del santo que recorre los caminos, las veredas, la cordillera para luego encontrarse con su compadre en su casa y permanecer ahí como invitado, y después actuar con reciprocidad en diversos sentidos: en el recorrido de la población, en la recepción con comida y bebida, en la fiesta que organizan y hasta en la participación de los alcaldes quienes comparten y reparten el conocido "chaparro" para todos los participantes. 


\section{Fotografía 6}

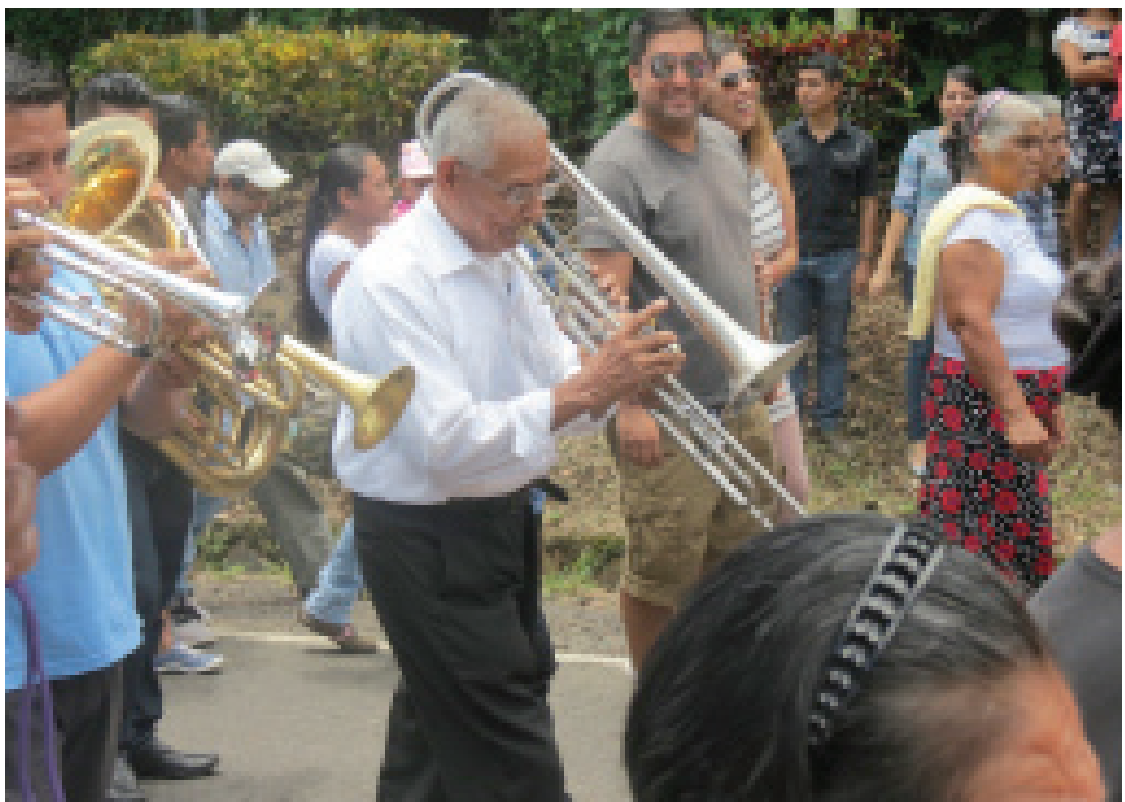

La banda del pueblo acompaña el encuentro de los Cumpas.

Un hecho que es controversial dentro de las celebraciones distintas es la participación de grupos de homosexuales provenientes de los pueblos indígenas que se integran en la cooperación y en las celebraciones, especialmente en los bailes en los cuáles hay bebetorias. No es un hecho que se evidencia en las celebraciones ni religiosas y ni laicas en otras regiones, ¿Por qué aquí sí?, se ha preguntado y la respuesta ha sido: "porque ellos colaboran más que otros". Ellos se sienten integrados en la celebración a partir de su cooperación para el encuentro y no hay rechazo de las cofradías, más bien hay acogida.

Los santos, cumpas, los compadres son amigos, no solo lo son los cofrades, lo son también los santos que están animados, que están vivos, que tienen amistad, que se visitan, y que devuelven la visita. El santo camina en hombros de los peregrinos por la cordillera para cruzar los casi treinta kilómetros en línea recta por la cordillera hasta llegar a Jayaque un recorrido que ellos pueden recorrer en poco más de cuarenta horas, en tanto grupos de peregrinos aparecen en las lomas, las quebradas, los caseríos y los cantones y se suman, ese serpenteo se hace cada vez más grande.

Todas las cofradías participantes, tienen como sede original a pueblos con origen indígena. En casi todos ellos aún existen nahuablantes, en ciertos casos son muy pocos eso sí, pero existen. 
En otros pueblos como San Antonio del Monte o Jayaque, la modernidad, la influencia mediática, hace menos notoria la existencia de población originaria o indígena, y eso casi invisible también a la lengua nahuat, pero hay evidencias de una vinculación de la población actual incluyendo el casco urbano con los pueblos originales que se expresa simbólicamente en los nombres de los pueblos, los cerros, los ríos, los apellidos de la gente, los valores, sus costumbres, sus alimentos y la relación con la naturaleza entre otros.

\section{Las cofradías y la iglesia de San Lucas Cuisnahuát}

En Cuisnahuát existen dos cofradías, o al menos así lo señala el párroco de la localidad, aunque una de ellas es más un Concejo de Iglesia que una cofradía, está más sometida a la voluntad y poder del párroco y no representa a la población en general. Es una cofradía reciente creada para la advocación de San Lucas venerado en la imagen que le fue entregada al Párroco en un episodio que se comenta adelante. (Martínez C. , 2018)

La otra cofradía es más antigua, con mayor raigambre en la población, más independiente y más dinámica. De hecho, es la que promueve la visita de "los cumpas". La relación de esta cofradía con el sacerdote es muy lejana y esta relación poco amigable parece tener su origen en la "devolución" de las imágenes sacras que anteriormente estaban bajo su tutela, un hecho atribuido a una antigua miembro de la dicha cofradía ${ }^{6}$, mayordoma en su momento, que sin considerar las opiniones del resto de los cofrades elaboró un acta de entrega de las imágenes que pertenecían a la cofradía, y sobre las que se sustenta su advocación: "Cofradía de San Lucas Evangelista".

6 Rhina N. 


\section{Fotografía 7}

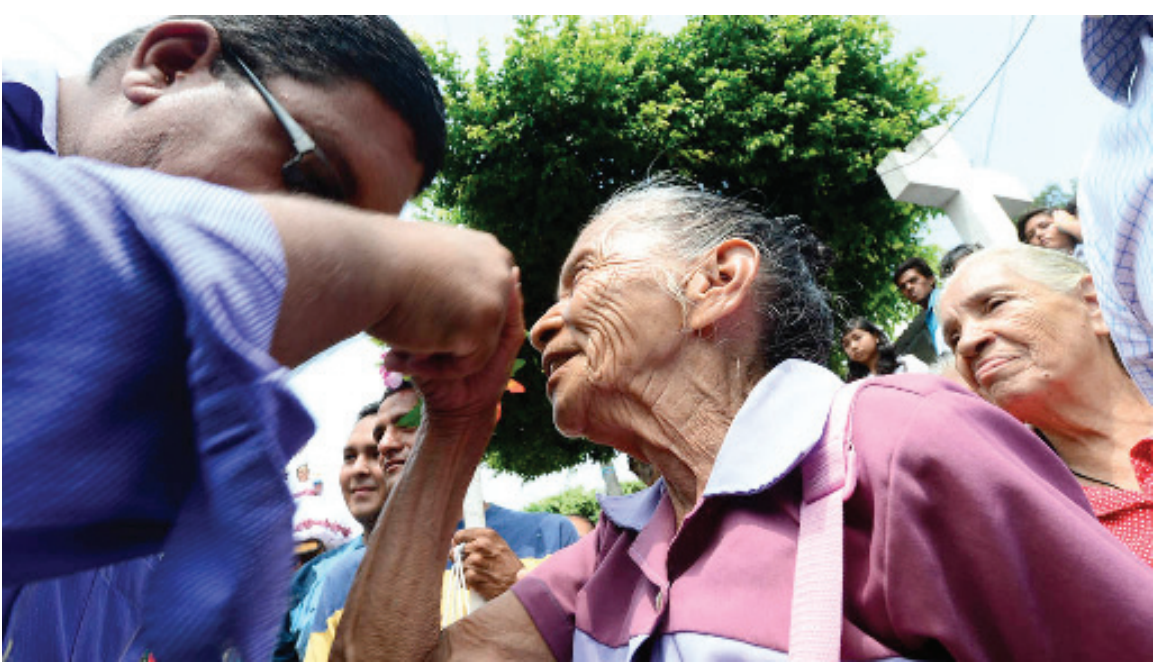

Saludo tradicional de los Cumpas.

Fotografía. El Diario de Hoy

Esta persona investida con el poder de la mayordomía, por alguna razón que no conocemos determinó que "esta cofradía se termina" a pesar de la negativa del resto de los cofrades que se aferraban a las tradiciones (Pedrina Figueroa Pérez, 2017) y procedió a la entrega, a la iglesia local, de la imagen de San Lucas que tenía ya mucho tiempo, décadas de estar bajo la tutela de la cofradía, el hecho ha tenido tales repercusiones que ahora mismo hay dos "San Lucas", uno que está en poder de la iglesia institucional y el otro que se encuentra bajo la tutela de la cofradía local, y que ya ha tenido dos primeras visitas a San Cristóbal en Jayaque. (Pedrina Figueroa Pérez, 2017)

Hay otros símbolos que no fueron entregados a la iglesia institucional, que permanece bajo la custodia de la población local representada en la cofradía como "la vara de insignia" hecha de plata, que se compone de nueve canutos de un pie (treinta centímetros), una vara de armar que se guarda en caja de madera. La insignia tiene la imagen de San Cristóbal y de San José. Esta vara es usada para los rituales de "los cumpas" originales. (Miguel Angel Quintanilla, 2018)

No es este el único hecho que divide al párroco de la cofradía, el desarrollo de la romería de ida y vuelta de "los cumpas", teñido de costumbres paganas y probablemente relacionadas con las costumbres de los pueblos originarios, establece un valladar entre actores de la religiosidad de Cuisnahuát. 
Talvez, en lo profundo haya algo que una folklorista salvadoreña de los años treinta expresaba: "Muchos (de los indígenas) no hicieron más que cambiar sus dioses paganos por las imágenes del culto católico. Efectuaban ceremonias religiosas católicas... pero seguían adorando a sus dioses" (Baratta, 1934)

\section{Fotografía 8}

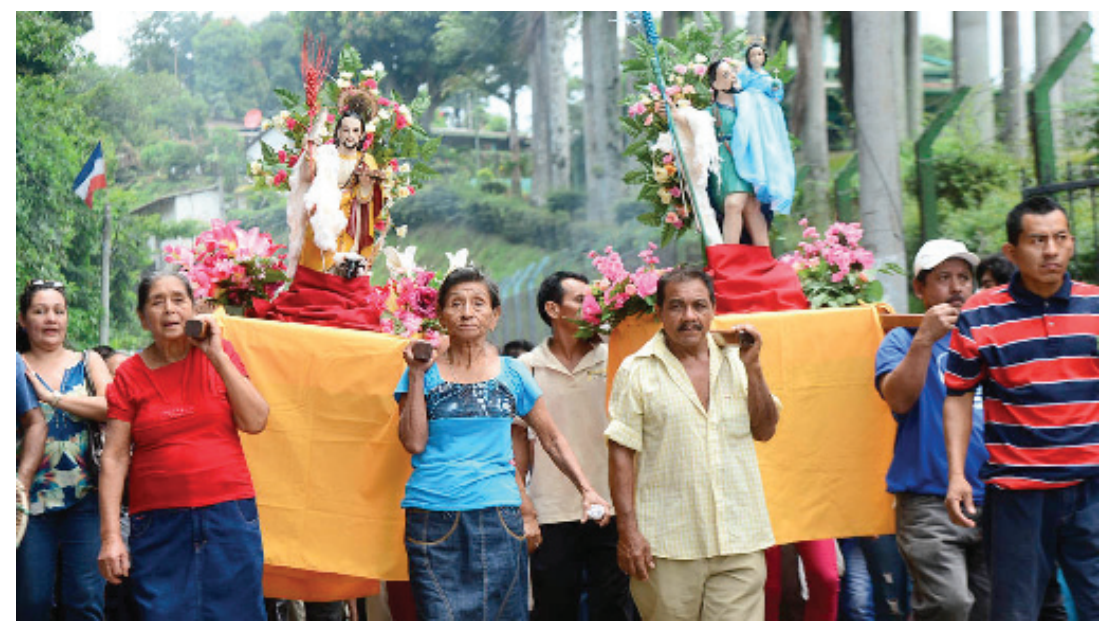

Procesión de las cofradías.

Fotografía. El Diario de Hoy

\section{La peregrinación}

El día 22 de julio, es un día importante para la población de Cuisnahuát, antes de ese día los que harán la peregrinación o romería se preparan en distintas formas. Es un recorrido en el que se debe organizar anticipadamente los preparativos para que haya ninguna falla, hay una preparación importante que hace notar que este es el acontecimiento más importante del año en la vida de la sociedad del pueblo.

El día de salida, los peregrinos llegan con sus previsiones para el viaje, zapatos adecuados, toallas, y comida para el viaje, gallinas, pollos, queso, tortillas y demás, aunque esto parece estar de más. El recorrido se hace no por la carretera en donde quizá sea un poco más largo, pero menos complicado. La gente prefiere seguir la tradición de usar la cordillera como ruta de viaje. Una de las cofrades resume el viaje de dos días:

"Aquí nos vamos en la calle de San Julián, de la calle cruzamos por Chilata y luego a Tierra Colorada, por veredas y llegamos a las Crucitas, que es una calle difícil. Y a pura devoción trepamos cuestas y bajamos, a las doce vamos llegando. Dormimos en Tepecoyo, salimos de ahí a salir a Curazao, en donde 
les hacen misa y después nos vamos así... caminando, caminando" (Pedrina Figueroa Pérez, 2017)

Sin duda, la peregrinación es casi una penitencia. Los pobladores en número menos a un ciento (70 a 80 niños, jóvenes y personas de la tercera edad) salen de Cuisnahuát para hacer una primera estación en la cueva del Estocal, una formación pétrea cavernosa a unos cinco kilómetros de Cuisnahuát, en la que con alguna facilidad bien caben unas doscientas personas. Luego se sigue la ruta antes descrita por las montañas de la cordillera, los cohetes de vara van avisando el paso de la romería, a la que se van juntando pobladores que van saliendo de las casas de sus cantones para sumarse a la fila de peregrinos, y convertir la pequeña peregrinación en un río que sube y baja por los cerros con un enorme caudal.

Los que no se suman, salen a encontrarles para brindarles una tortilla, un pan, un pocillo de café, un pedazo de queso y de paso saludar a San Lucas, que va de viaje.

"En la peregrinación que realizan está incluido el Cerro conocido como las cruces, ubicado en la cordillera del bálsamo, a una altura de $1260 \mathrm{msnm}$, donde habitantes de Tepecoyo ayudan a los peregrinos a cargar los camarines, iniciando el descenso hasta Tepecoyo, haciendo una estación previa en el cerro conocido como las Cruces, su avance es anunciado por cohetes de vara, que hacen resonar los cielos de la cordillera..." (García, 2015)

Se hace una estación del recorrido para descansar la noche, esta es en Tepecoyo (Tolentino, 2015), en donde la romería se transforma en algarabía, en una fiesta en donde la pirotecnia busca un lugar, la misa se vuelve solemne y además, hay una fiesta con chaparro y chicha, como un amarre a la antigua tradición de los pueblos originarios, la fiesta para que sea fiesta debe contar con chicha:

"Alrededor de las 11:00 de la mañana, el sonido de los cohetes de vara anunciaba la llegada de los peregrinos y las imágenes, que fueron recibidos por los feligreses con mucha alegría y solemnidad. Allí se llevó a cabo el tradicional saludo de estos conocidos santos compadres." (Villalta, 2014)

Los cofrades del lugar, los o las mayordomas se encargan de proveer los alimentos para los peregrinos que han llegado a la topa de los cumpas. Los anfitriones se responsabilizan por la alimentación y el hospedaje de los que llegan, pero esto es así en cada caso:

"Cuando nosotros invitamos, los tres días que están aquí, nosotros les damos de comer, y cuando vamos ellos nos tienen que invitar". (Miguel Angel Quintanilla, 2018) 
Los santos se encuentran se saludan, se topan, se abrazan en el encuentro que es el momento más importante de la tradición.

Si bien es cierto que hay una celebración de la misa, esta adquiere un tono más severo, más solemne que el resto de la celebración que implica una fiesta en la que se distribuyen cigarros, chicha y chaparro. Todo ello (excepto la chicha que se regala) origina ingresos que sirven para poder aliviar los gastos en que se ha incurrido:

"El baile es cobrado y se venden cigarros y puros, el baile vale una cora" (Pedrina Figueroa Pérez, 2017)

Esos gastos puede que no sean tan pocos, ya que consiste en dar de comer durante dos o tres días a los invitados que pueden sobrepasar las cincuenta personas. Algunos de los egresos en que se incurre son donaciones o resultados de actividades en las que se logra obtener algunos fondos, pero es necesario desde luego, recuperar algo:

"La capitana tiene costos y debe sacar algo, para eso se cobra el baile" (Miguel Angel Quintanilla, 2018)

¿Qué hace la chicha o el chaparro en una tradición religiosa, católica más expresamente siendo que algunos de los sacerdotes sino todos no están de acuerdo con ello? De regreso a Baratta, Las Casas, Sahagun y otros: Es que en muchos casos los indígenas parecían obedecer y asumir la ideología cristiana (Baratta, 1934), sin embargo en sus casas u ocultos en la montaña, mantenían su tradición de adorar a sus propios dioses, ello también implicaba la bebida de la chicha en comunidad y en algunas etnias precolombinas el uso de psicotrópicos vegetales para amplificar los sentidos.

Por otra parte, la ebriedad era parte inseparable de la manera como los indígenas eran percibidos por los españoles:

“...los ven los curas, pero no se espantan, porque aunque sean ebrios, lascivos, incestuosos, adúlteros, plagiarios y demás, pero criados desde niños entre tales monstruos no se espantan, ni aun se inmutan ligeramente, como si dejaran de ser tales por serlo de costumbre" (Cortez y Larraz, 2000)

Probablemente el encuentro original como mencionado al inicio, era de intercambio de productos y ofrendas entre los pueblos indígenas.

"La tradición de beber chicha o chaparro tiene muchos años, desde los años 1660, la tradición es dar ocho litros de chicha en el baile, si viene Jayaque los atendemos. Si nosotros vamos allá ellos deben poner los mismos ocho 
litros de chicha. El chaparro es otra cosa, eso lo pone el alcalde, el reparte el chaparro, reparte chicha. Pero la tradición la mantiene la cofradía” (Miguel Angel Quintanilla, 2018)

Los alcaldes pueden repartir cantidades poco imaginables de chaparro cuyo efecto es superior y más inmediato que la chicha. Los niveles de alcohol del chaparro pueden superar los setenta grados.

A esta festividad popular que deja a un lado el carácter religioso del santo, que le da vida y le transforma en un ser humano, animado, le siguen otras actividades de alegría, no devocionales:

"hubo una tarde artística, carreras de cintas y reparto de tamales, chocolate, chicha y el típico nancito ${ }^{7}$, una bebida macerada con chaparro que es tradicional para esta festividad.

Por la noche hubo quema de pólvora y se contó con la presentación de la orquesta Amigos Band, que puso a bailar a los habitantes y visitantes del municipio.

Hoy, en horas de la madrugada, los santos iniciaron la peregrinación para llegar a la entrada de Jayaque, donde serán recibidos por la cofradía de San Cristóbal". (Villalta, 2014)

De tal manera que los juegos, el entretenimiento, el chaparro, la chicha, la música, el baile, la comida y en fin el hartazgo, forman parte del encuentro de los cumpas, un encuentro sincrético en el que los pueblos originarios parecen apropiarse culturalmente del cristianismo católico y se salen con la suya, ejecutando una fiesta en la que se celebra la amistad, el encuentro, lo lúdico y se bebe para hermanarse aún más.

La tradición cobra sentido no solo por lo cristiano sino también por lo pagano, la comunidad se junta y lo celebra, se emborracha y acompaña al santo, camina por las veredas y la cordillera para celebrar que el santo hecho hombre visita a su compadre. La tradición se mantiene viva:

"En el recorrido participan niños, jóvenes y personas de la tercera edad, como Domingo Flores, de 88 años, quien desde que tenía 12 años ha participado en esta celebración y es uno de los encargados de amenizar la caravana al ritmo de un tambor". (El diario de hoy, 2013)

7 Es época de nances, un frutilla tropical de sabor amargo dulzón, "tetelque". Los nances se meten en pequeños botes a los que se agrega chaparro, que va adquiriendo el sabor de la frutilla. 


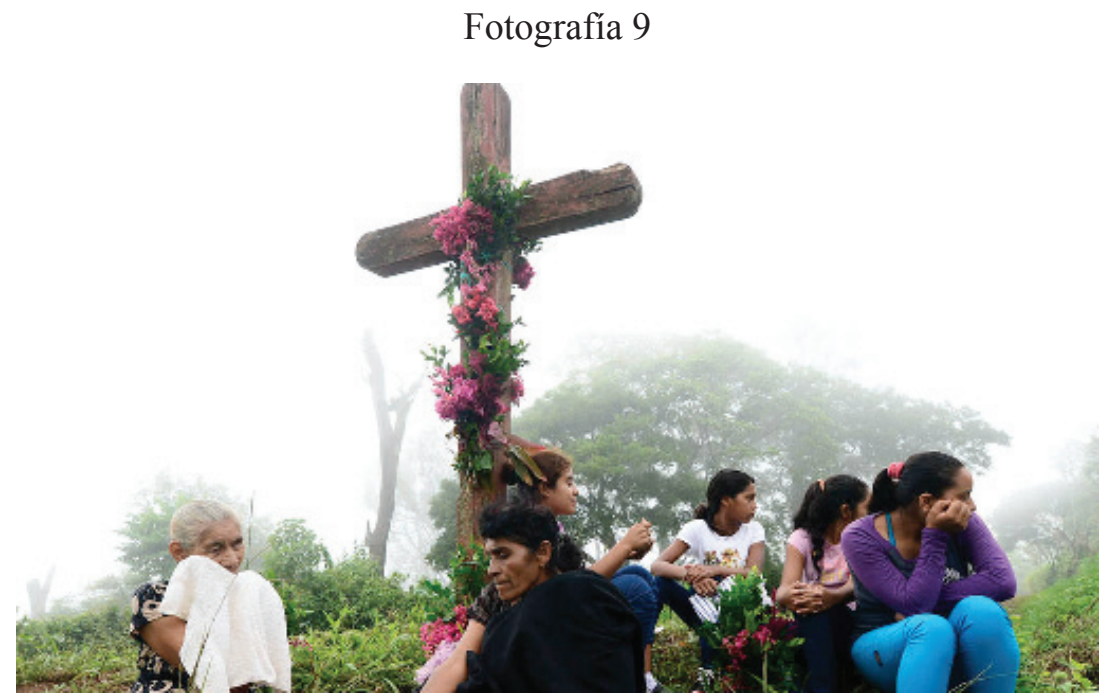

Cofrades realizando un descanso.

Fotografía. El Diario de Hoy

\section{La topa de los cumpas}

La caminata ha logrado uno de sus fines, la fraternización, con ello también ha cumplido la función social de la religiosidad que es la de establecer una comunidad estrecha. Los cofrades como representantes también tienen su propio ritual:

"Mientras esto ocurre, las cofradías de cada pueblo se colocaron en fila para realizar el encuentro conocido como la "Topa de los Cumpas", donde realizan un saludo fraternal". (El diario de hoy, 2013)

Más adelante, las imágenes en hombros van caminando para encontrarse de nuevo como lo han hecho desde hace trescientos cincuenta años, el sol, la pendiente, el pavimento, el peso de los santos hacen que los encargados de la carga suden y se sientan desfallecer, a esta altura el punto de reunión, el lugar de la "topa" ya se ha llenado de gente, de grupos danzantes como "los historiantes", ${ }^{8}$ de vendedores y de visitantes externos que curiosos van a ver la topa, en las calles ya hay dos o tres mil personas esperando el encuentro de los cofrades que ya cuentan con los regalos de intercambio con sus pares.

8 Los historiantes es el nombre local con el que se conoce a los Moros y cristianos en la región 
Fotografía 10

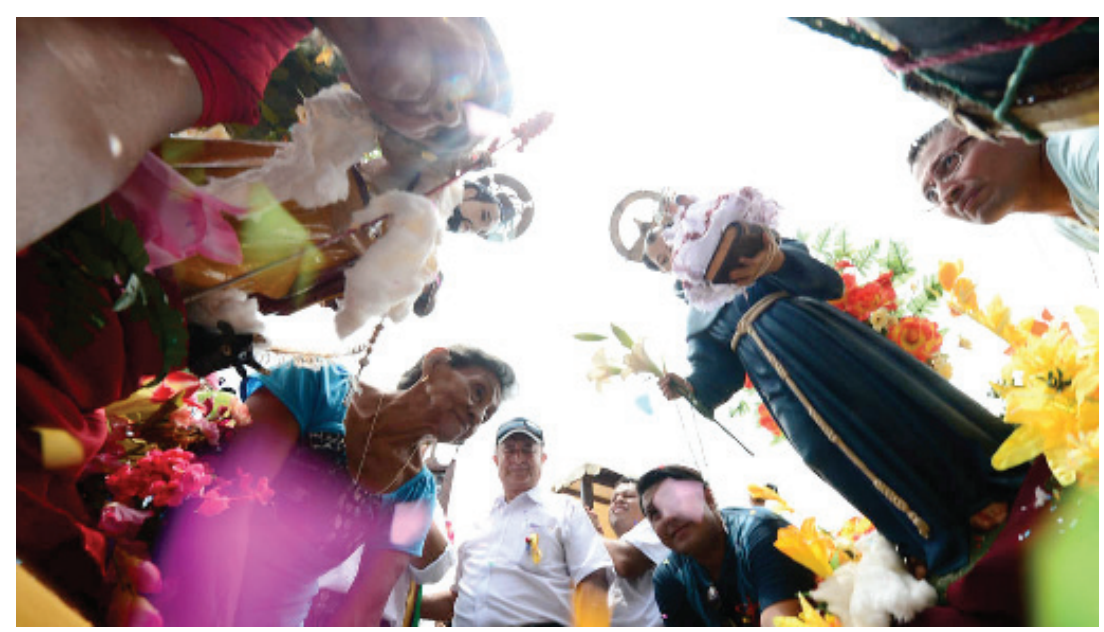

Cofrades realizando su encuentro en Tepecoyo.

Fotografía. El Diario de Hoy

La majestuosidad del encuentro adolece de la figura del sacerdote, quien se encuentra en la iglesia solo esperando la llegada de los santos. En este encuentro religioso mandan los cofrades y los mayordomos. La alegría de la población sobrepasa lo espiritual, el rito es amenizado por un sonsonete repetitivo del pito y el tambor, los historiantes han comenzado su danza por toda la calle, los piteros tres, cuatro o cinco siguen amenizando:

“...con el son de la música San Esteban y San Antonio comienzan a avanzar, San Antonio que va acompañado al son del pito, el tambor y cohetes, se detiene y ambos santos hacen una reverencia inclinándose; continúa avanzando y a pocos metros ambos santos nuevamente hacen una reverencia, continúa avanzando San Lucas hasta llegar donde San Esteban, finalmente, en la última reverencia topan sus cabezas; en ese momento la banda toca una diana, la gente aplaude y tiran confetis. Después dejan a los Santos juntos, viendo hacia donde aparecerán las imágenes de San Lucas y San Cristóbal listo para saludar, siendo esta la parte más solemne del encuentro". (García, 2015)

Ya los santos se han saludado en esta animación que le profieren los peregrinos, y se dan por bienvenidos los visitantes, y desde luego, también San Lucas se siente bienvenido.

Es el turno de los cofrades, siguiendo el ejemplo de los santos, realizan su propia "topa", este ritual trata sobre el encuentro de los cofrades quienes se dan 
la mano derecha y luego como en señal de respeto y amistad, de fraternidad, la pone en la frente del visitante diciéndole: "Bienvenido hermano cumpa".

\begin{abstract}
“Luego se saludan las cofradías9. La cofradía visitante se coloca en semicírculo amplio, la cofradía local se coloca en una fila, el primer mayordomo va adelante y comienza a saludar a cada uno de los visitantes y lo mismo van haciendo todos los demás miembros de la cofradía, la representante municipal, como en épocas del siglo diecisiete, era los alcaldes, en esta ocasión La Alcaldesa Janet González hace entrega de regalos a los alcaldes visitantes, y a los mayordomos de las cofradía, esto como signo de amistad, entre los dos pueblos" (García, 2015)
\end{abstract}

\title{
Referentes bibliográficos
}

(25 de marzo de 2018). Obtenido de Mi pueblo y su gente: http://www. mipuebloysugente.com/apps/blog/show/43097778-jayaque-la-libertad Alcaldía Mpal. de Jayaque. (1861). Informe 20 enero 1861.

Baratta, M. d. (1934). Cuzcatlán típico: ensayo sobre etnofonía de El Salvador. San Salvador, El Salvador: Publicaciones del Ministerio de Cultura.

COMURES. (2015). En Tepecoyo se juntan cuatro municipios por la tradición. ¿Que hacen nuestros agremiados?, 1-3.

Cortez y Larraz, P. (2000). Descripción geografico moral de la diócesis de Goathemala. San Salvador, El Salvador: DPI.

Cuisnahuat, C. d. (noviembre de 2017). carta al párroco de Cuisnahuat. Cuisnahuat, Sonsonate, El Salvador.

El diario de hoy. (23 de julio de 2013). Los cumpas unen a fieles de tres municipios.

FISDL. (2010). Cuisnahuat.

García, J. (2015). El tradicional encuentro de los cumpas. Tepecoyo: s/e.

Martínez, C. (16 de marzo de 2018). Los cumpas. (J. Martínez, Entrevistador)

(18 de marzo de 2018). Miguel Angel Quintanilla. (J. Martínez, Entrevistador) Cuisnahuát, Sonsonate, El Salvador.

(16 de diciembre de 2017). Pedrina Figueroa Pérez. (J. Martínez, Entrevistador) Cuisnahuát, Sonsonate, El Salvador.

Ramírez, C. (15 de marzo de 2018). Santos y topas. (J. Martínez, Entrevistador) Ruiz, P. (18 de Octubre de 2017). los cumpas en Cuisnahuat. (J. Martínez, Entrevistador)

Tolentino, J. (2015). Tepecoyo. San Salvador.

Villalta, M. (22 de julio de 2014). El encuentro de los cumpas. El diario de hoy.

9 Es el mismo gesto que hacen los santos, los cofrades emulan al santo en el encuentro. La cofradía adquiere un valor importante y destacado en el encuentro. 


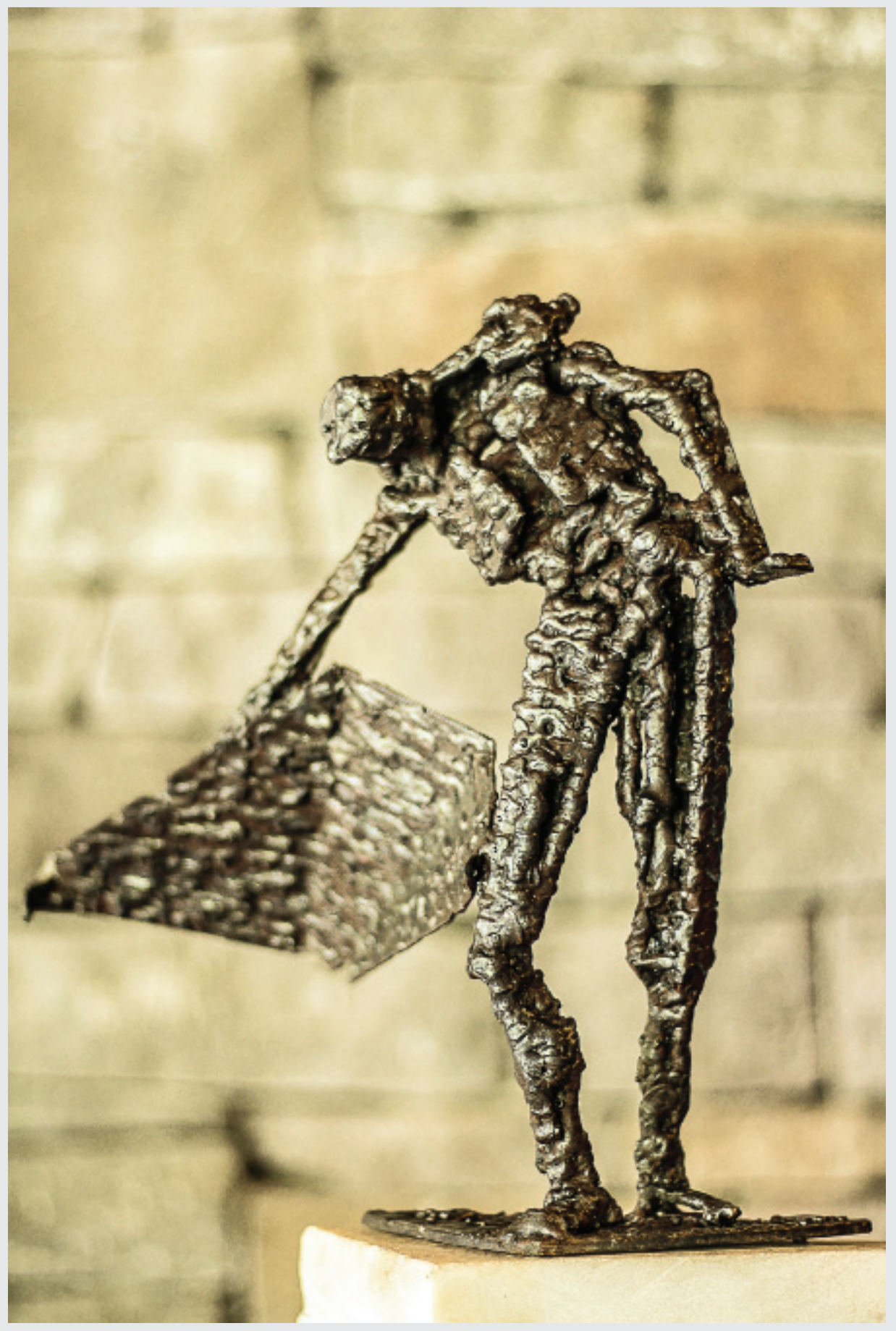

Rubén Martínez, Bulnes 